\title{
Identification of Ajnala skeletal remains using multiple forensic anthropological methods and techniques: a bioarchaeological report.
}

SEHRAWAT, J.S., RAI, N. and MEIER-AUGENSTEIN, W. 


\title{
Identification of Ajnala skeletal remains using multiple forensic anthropological methods and techniques: A bioarchaeological
} report.

\author{
J.S. Sehrawata, ${ }^{\star}$, Niraj Raib, Wolfram Meier-Augensteinc \\ a Department of Anthropology, Panjab University, Chandigarh 160014, India \\ $\mathrm{b}$ Birbal Sahni Institute of Paleosciences, Lucknow, Uttar Pradesh, India \\ c Stable Isotope Forensics, Robert Gordon University, Aberdeen, AB10 7GJ, Scotland, United Kingdom
}

\section{A B S T R A C T}

Fragmented and badly damaged commingled human remains present a tough challenge for their identification pursuits in forensic anthropology. Thousands of unknown human remains along with items of contextual identity, reportedly belonging to 282 Indian sepoys killed in 1857, were exhumed non-scientifically from a disused ancient well at Ajnala (Amritsar, India). In this manuscript, the non-scientific excavation of unknown human remains from the abandoned well, their forensic anthropological strategies for identification purposes, challenges being faced and future possibilities of their biological profiling have been discussed. Multiple methods and techniques like anthropological examinations, odontological profiling, radiological analyses, stable isotope and mitochondrial DNA (mtDNA) analyses were applied to few bones and teeth collected from the Ajnala skeletal assemblage. Though majority of studied bones and teeth were found belonging to adult males, very few of them had morphological, osteological and molecular features questioning the authenticity and validity of the written records. Due to certain ambiguous findings or gaps observed between the anthropological analyses of the Ajnala skeletal remains and the reported versions about their affiliations; certain advanced radiological, chemical and molecular techniques were applied to estimate their probable age, sex and populational affinity. The obtained radiological, isotopic and molecular signatures of the remains were compared with the available databases to estimate their affinity with the individuals of geographic area to whom the remains reportedly belonged to. The maternally inherited mtDNA haplogroup assignments, and stable isotope analysis of carbon and oxygen suggested that the studied human remains belonged to the individuals from West Bengal, Bihar, Odisha, Awadh (presently in Uttar Pradesh) and parts of Meghalaya and Manipur as potential regions of their geographic identity and thus, attributing the victims to be non-local to the site. However, merely on the basis of forensic anthropological examinations of very few bones and teeth (collected out of a huge collection of thousands of bones and teeth); it would be just an unqualified and sweeping conclusion to claim their identity as adult or non- adult, male or female, local or non-local, victims of 1857 mass killings or to the victims of ceremonial sacrifices or criminal activities committed in the past. A sufficient number of bones and teeth along with items of personal identity needs to be examined with multiple scientific techniques to arrive at some valid conclusions about their biological identity.

\section{Keywords:}

Forensic anthropology; Ajnala skeletal remains; Identification; Non-scientific excavation

\footnotetext{
* Corresponding author. E-mail addresses: jagminder@pu.ac.in (J.S. Sehrawat), nirajrai@bsip.res.in (N. Rai), w.meieraugenstein@rgu.ac.uk (W. Meier-Augenstein).
}

https://doi.org/10.1016/j.jasrep.2020.102434

Received 4 November 2019; Received in revised form 10 June 2020; Accepted 10 June 2020 


\section{Introduction to the human remains:}

An abandoned well situated underneath a religious structure at Ajnala (Amritsar, India) was excavated non-scientifically by some local people, after getting information from the written records in the form of a book and the local gazetteers. Thousands of human skeletal and dental remains along with contextual items of identity were exhumed from the well sediments, after re-locating the religious structure to an adjoining place. The written records mentioned that the retrieved human remains belonged to 282 mutineer Indian soldiers killed by the colonial rulers on August 1, 1857 (Cooper, 1858; Bates and Carter, 1857). The cadavers of multiple victims were dumped into a disused well and a religious structure was erected over its periphery to disguise the mass burial site (Fig. 1). The existence of such human remains in the ancient well were brought to attention only in early 2014 when someone from the region happened to read the book (The crisis in Punjab: From 10th of May until fall of Delhi) written by the then British Magistrate and Commissioner of the region in 1857 (Cooper, 1858).

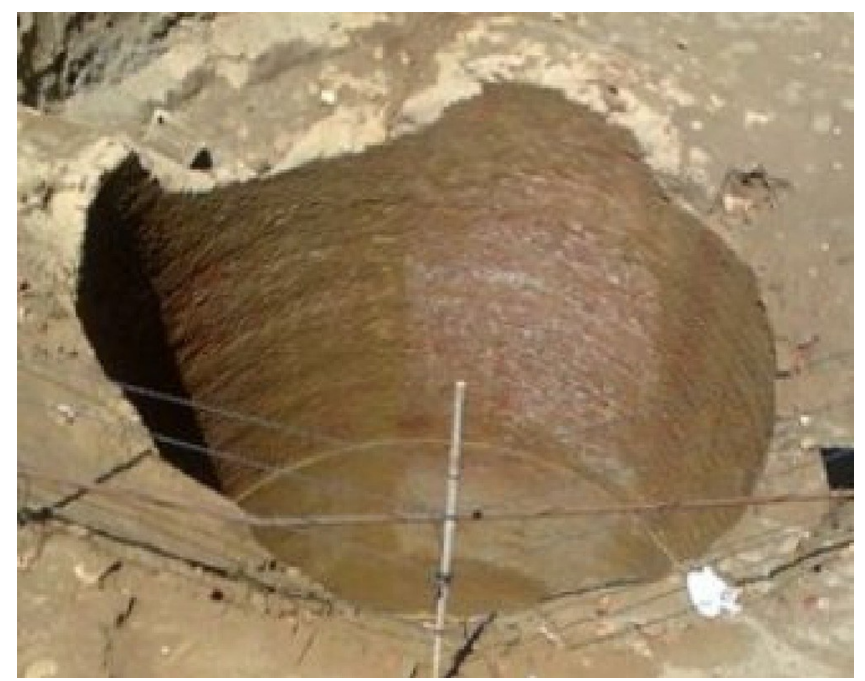

Fig. 1. Geomorphometry of the Ajnala well after its excavation.

The government authorities didn't consider the media reports or written records as authenticated proofs and were apprehensive that it might prove to be another fake claim similar to another contemporary Unnao gold treasure incident of October 2013. A saint from Unnao (Uttar Pradesh, India) had dreamed about the presence of a gold treasure buried underneath an old temple at 'Dandiya-Khera' village (Unnao, Uttar Pradesh, India) which, later on, was proved a hoax dream after when the dreamed site was completely excavated by Archae- ological Survey of India (ASI) to find nothing (https://www.indiatoday. in/india/north/story/unnao-gold-treasure-archaeological-survey-of- india-swami-shobhasarkar-215482-2013-10-25 accessed on 12.7.2019). The religious structure (built over the Ajnala well) was relocated to an adjoining place and the well was excavated in early 2014 to dig out the human remains reported to be buried in it (Cooper, 1858; Bates and Carter, 1857). The government agencies swung into action only after the remains were dug out by the amateur archaeologists. The non-scientific excavations led to heaps of badly damaged and discouragingly commingled human remains (Fig. 2) which included few intact skulls, dislodged teeth, fragmented jaw fragments, temporal cranial pieces, some infra-cranial 
skeletal elements (like the clavicles, femoral heads, vertebrae, fragmented long bones, phalanges and foot bones like tali, calcaneus, metatarsals) in the exhumed skeletal assemblage from the well at Ajnala. Few contextual items like coins, medals, bracelets, rings, metalloid arm-bands, gold beads and amulets, bangles were also retrieved among the osseous debris spread at the site which anthropologically showed their identity link with the incident reported in the book. Presently, all the human remains along with the recovered contextual items are housed in the laboratory of the first author. Few amateur historians also doubt the factual authenticity of reported incident and have forwarded their own unexplained views about the identity affiliations of these skeletal remains (Sehrawat et al., 2016). Thus, identification of Ajnala skeletal remains is a seriously complicated issue/puzzle to be resolved from their forensic anthropological examinations by the investigators.

\section{Materials and methods}

All the well preserved skeletal elements were analysed morphologically using traditional forensic anthropological methods and techniques to estimate their sex, age and populational affinity (Sehrawat et al., 2016). The minimum number of individuals (MNI) was obtained by dividing the total number of the teeth types recovered by the actual number of those tooth types in a normal human oral cavity. As the teeth had good anatomical structures and were retrieved in fairly good numbers, so MNI was reconstructed from teeth counts only. Two hundred and forty-six ( $N=246)$ molar teeth of contemporary Indian nationals were also collected from the dental hospitals of tricity of Panchkula, Mohali and Chandigarh, including the Oral Health Centre of Govt. Medical College and Hospital, Chandigarh (UT) which were examined by applying similar methods and techniques as used for analysis of Ajnala skeletal remains. A well-informed written consent was obtained from the subjects prior to the collection and inclusion of their 'to-be-discarded off' teeth for present analyses. The age of the excavated skeletal remains was estimated from the morphoscopical skeletal features, third molar eruption patterns (though highly unreliable), epiphyseal union of proximal ends of the intact femurs and clavicles, pulp-tooth area ratio (PTR) of molars, elemental profile and the average attrition stage (ASA) method of molars. Sex was estimated on the basis of morphoscopical feature of different skeletal elements like flared zygomatic bones of intact crania, presence of nuchal crests, pronounced external occipital protuberance, larger mastoid processes, vertebrae and occipital condyles, pronounced supra-orbital ridges, larger shape and size of vertebrae and calcaneus, bone lengths of intact femurs and hand and foot bones (Fig. 3). Sex of 257 Ajnala mandibular molars was also estimated from the customized statistical formulas generated from the odontometrics of 254 known teeth of Indian subjects. The discriminant function and regression equations generated separately from eight odontometric measurements and elemental values of known molars were applied to the odontometrics and elemental profile of unknown Ajnala teeth; D-estimates were calculated and probable sex and age of ancient teeth was estimated (Sehrawat and Singh, 2020). The pulp-tooth area ratio (PTR) calculated from radiographic images of known canine teeth was applied to Ajnala samples to estimate their age and sex. Thirty molars were subjected to mtDNA (extraction, amplification, quantification and comparative analysis) and stable isotope analysis to correlate the obtained mitochondrial DNA (mtDNA) sig- natures and isocapes with the database available in the literature for the individuals of the geographical regions as mentioned in the written records (Cooper, 1858). 

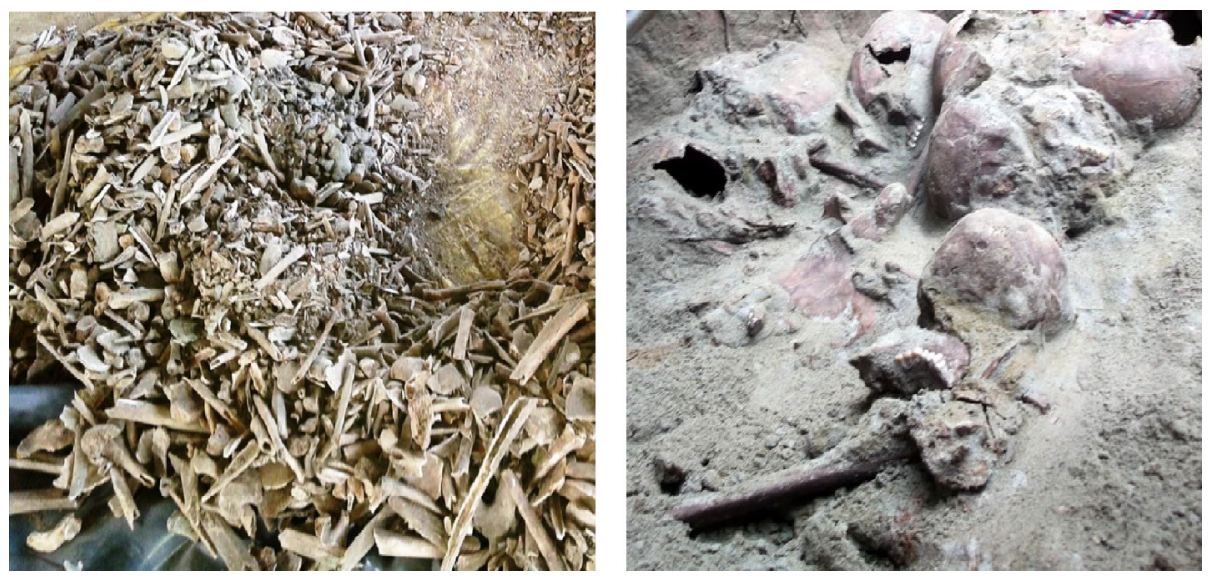

Fig. 2. Badly damaged and commingled human skeletal remains.

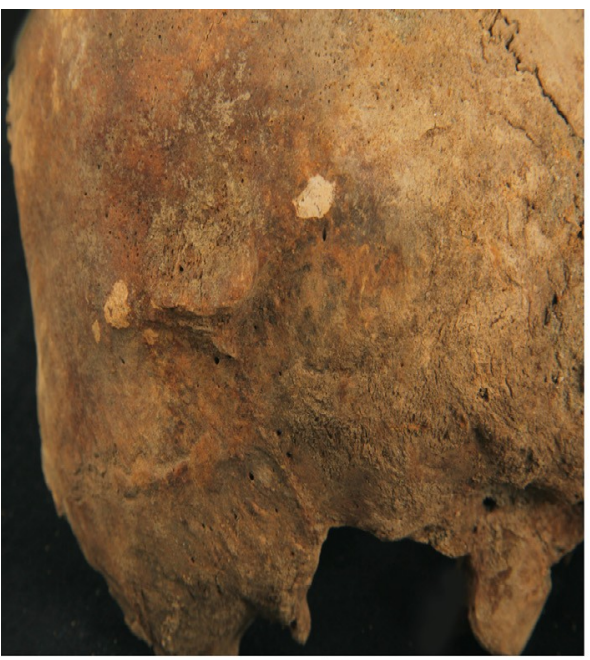

(a)

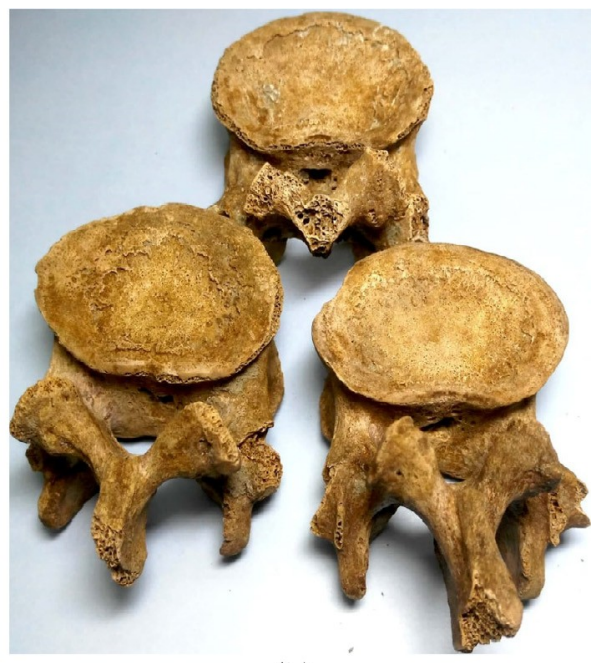

(b)

Fig. 3. a Pronounced occipital protuberance, nuchal ridge and large mastoid process; 3b: larger vertebrae (masculine features).

The stable isotopic abundances of carbon and oxygen in the carbonate fraction of tooth enamel were analysed from 46 Ajnala teeth samples (Sehrawat and Sankhyan 2020). Scale calibration of measured

$\delta$-values was carried out according to IUPAC guidelines (Coplen, 2011; Meier-Augenstein and Schimmelmann, 2019). Specifically, measured $\delta^{13} \mathrm{C}$ values were scale calibrated using in-house standard Merck- $\mathrm{CaCO}_{3}$ (consensus $\delta{ }^{13} \mathrm{CVPDB}_{\mathrm{VPB}}=-46.90 \%$ ) and international standard B2241 ( $\delta{ }^{13} \mathrm{CVPB}_{\mathrm{VPB}}=+2.10 \%$ ) as scale anchors while international standard NBS $18\left(\delta{ }^{13} C_{V P D B}=-5.01 \%\right.$ ) was used as quality control. Measured $\delta{ }^{18} \mathrm{O}$ values were scale normalized on the VSMOW scale using reference materials NBS 18 and B2214 as scale anchors based on their accepted $\delta 18$ Ovsmow values of +7.20 and $+28.85 \%$ o respectively. Calcium carbonate obtained from Merck (Product ID \# 102066) with a consensus $\delta 18$ Ovsmow value of $+17.31 \%$ was used as quality control. Precision of measurement as determined by analysis of NBS 18 was $\pm 0.10 \%$ for both $\delta{ }^{13} \mathrm{C}$ and $\delta$ $18 \mathrm{O}$ values. The statistical analyses were carried out to estimate the significance of differences in the results between values of Ajnala and modern teeth samples (used as 
reference standards) and interpretations were done. For detail methodology and techniques used for stable isotope and mtDNA analyses, the readers can consult the supplementary file attached with this article.

The extracted, amplified and quantified mtDNA from $30 \mathrm{M}$ was subjected to complete mtDNA sequencing using Next Generation Sequencing platform. Mutations were counted against the Revised Cambridge Reference Sequences. The observed set of mutations was subjected to HaploGrep2 software (https://haplogrep.uibk.ac.at) to assign DNA haplogroups to each sample. The obtained haplogroups were compared with a database compiled from the published mtDNA sequences from modern South Asian individuals (Tamang et al., 2018). Studies from Pakistan and India were being considered in the database because these regions of South Asia have been widely studied and were part of the larger subcontinent prior to the partition (Bandyopadhyay et al., 2017)

\section{Results}

As teeth were found better preserved compared to the bones, they were used for age and sex estimations of the remains from their odontometric measurements, pulp-tooth area ratio (Sehrawat et al., 2017), elemental analysis (Sehrawat and Singh, 2020), average attrition stages, and also for stable isotope and mtDNA analyses. The minimum number of individuals (estimated from count of 1st and 2nd mandibular molars) was calculated to be 246 (against 282 reported by Cooper, 1858). As majority of post-cranial skeletal elements were found badly damaged, they were discarded for forensic anthropological examinations. Later on, these fragmented osseous remains were immersed into the holy waters of river Ganges by the amateur excavators to perform their last rites/burials. The mandibles of few intact skulls were found still articulated to the cranium, supported by the soil sediments, and no purposeful articulation was done for any of the skulls. No articulated skeleton/s could be retrieved from the skeletal assemblage as no anthropologist, osteo-biologist or archaeologist was involved in this non-scientific excavation work carried out by the locals without any intervention from the government authorities. The dislocated teeth, few intact crania, fractured jaw fragments (having in-situ teeth, still fitted in jaw sockets), and bones like femur fragments, vertebrae, clavicles, talus, calcaneus, metacarpals, metatarsals, and contextual items sorted out of the commingled human osseous debris at the site have been shown in Fig. 2.

The forensic anthropological features of the retrieved intact skeletal elements revealed that the victims were adult males. Sex estimation based on application of customized statistical formulas generated from the odontometrics of known contemporary teeth of Indian origin found that more than $96 \%$ teeth belonged to males (Sehrawat and Singh, 2019). The beveled exit wounds on the frontal or fronto-temporal portion of 3-4 intact crania (Fig. 4) and the entry wounds present on their posterior aspect of a skull (Fig. 5a) showed that the wounds were possibly from a firearm weaponry. The traumatic lesions and impact impressions present in 18 intact crania revealed that few injuries were also caused by some blunt weapon/tool hammered on the skull of the victims (Fig. 5b); most likely during their non-scientific excavations by the amateur archaeologists who had used trowels or other blunt tools for the purpose. The use of blunt implements by the excavators during the excavation process was verified from the fieldwork interactions with few of them during field visits to the site. The coins and medals have indented inscriptions of the year of their make and the photograph of Queen Victoria which revealed that the retrieved human remains were likely to dropped into the well in and around 1857, and not in 1947 as none of coins/medals are dated later than 1856 (Fig. 6). The burial period of the remains has also been recently corroborated from C-14 AMS dating of some dentine collagen samples (Table 1). The calibrated age range (s) at 2-sigma and their probabilities were calculated for each 
radiocarbon date using the Northern Hemisphere Zone 3 dataset (Hua et al., 2013) with one year smoothing appended to IntCal13 (Reimer et al., 2013) and online software CALIBOMB (http://calib.org/CALIBomb/) from the '14Chrono' website hosted at Queen's University Belfast (Reimer et al., 2004). Though mean age couldn't be ascertained, but the calibrated dates do show high probabilities that remains belong to the 19th Century (Reimer et al., 2004, 2013; Hua et al., 2013). The morphological analysis of skeletal features, odontometric analysis and elemental profiling of Ajnala teeth found that more than $90 \%$ of studied teeth were from males (Sehrawat and Singh, 2019, 2020). Based on the radiographic pulp-tooth area ratio (PTR) of canines $(\mathrm{N}=703)$, it was found that majority of the teeth (87-90\%) belonged to adult males between ages of 20 to 50 years; though $13 \%$ of them were categorized to be of sub-adult females (Ajmal et al., 2001; Babshet et al., 2011; Sehrawat et al., 2017).
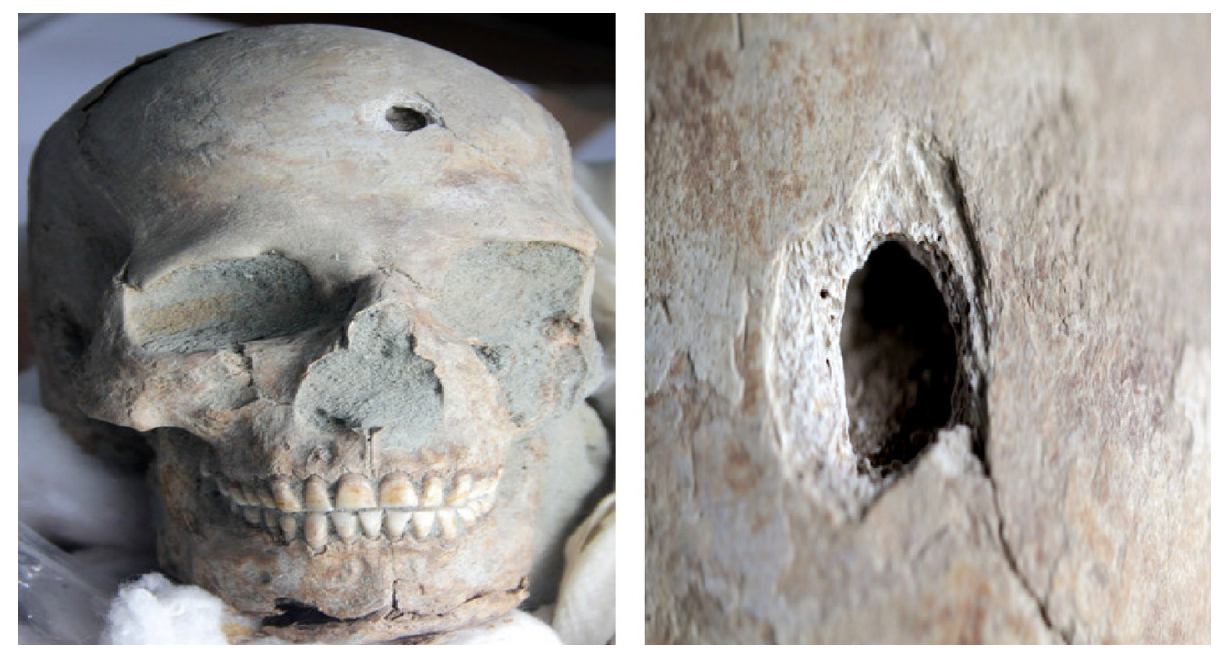

Fig. 4. Traumatic injury (possibly from a firearm weaponry) on a frontal skull recovered from Ajnala well (Sehrawat and Sankhyan, 2020)

Tooth enamel carbonate $\delta{ }^{18}$ Ovsmow values pointed towards $\delta^{18}$ Ovsmow values of source water in the range of -11.4 to $-4.8 \%$ (Daux et al., 2008; Chenery et al., 2012). The $\delta{ }^{13} \mathrm{C}$ signals observed (carbon signal of entire diet) were not correlated with $\delta 180$ signals of source water (Fig. 7). The stable isotopic values of carbon and oxygen were quantified and compared with the standardized values to assess dietary patterns, childhood residences and mobility status of the Ajnala victims. While the majority of the samples show $\delta{ }^{13} \mathrm{C}$ data consistent with carbon derived from a balanced omnivorous diet, there are nine individuals whose $\delta{ }^{13} \mathrm{C}$ values stick out. Five individuals show $\delta{ }^{13} \mathrm{C}$ values one would expect to see in primary consumers with a predominantly terrestrial $C_{3}$ plant based diet which is a potential indicator of a poor, low social standing background. Four individuals, on the other end of the spectrum, show $\delta{ }^{13} \mathrm{C}$ values that are either caused by a strong $\mathrm{C}_{4}$ plant influence, or a large proportion of animal derived protein, or, possibly, a combination of both.

The haplogroup distribution in the sequenced mtDNA found that the haplogroups $U^{*}, \mathrm{R}^{*}$ and HV* and G2a1d2 had higher frequencies in Ajnala mtDNA data (Fig. 8). The comparisons of haplogroup frequencies with the generated database further reflected that studied teeth samples belonged to individuals belonging to the Indian states of Bengal, Bihar, Orissa, Awadh (eastern UP), Manipur, Meghalaya and few other north-eastern and coastal Indian states (Bandyopadhyay et al., 2017, Sehrawat and Sankhyan, 2020). The Principal Component Analysis (PCA) of mtDNA haplogroup frequencies signified that ma- jority of 
them belonged to present day Pakistan $(N=8)$, Iran $(N=6)$ and Central Asia $(N=4)$; the remaining showing their affinity to Indian states of Punjab, Gujarat, Uttar Pradesh and Central and South Indians (Fig. 9).

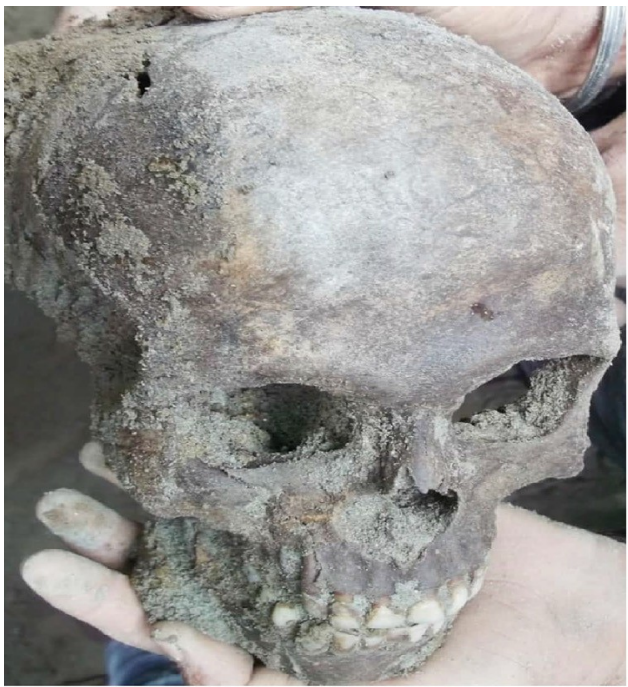

(a)

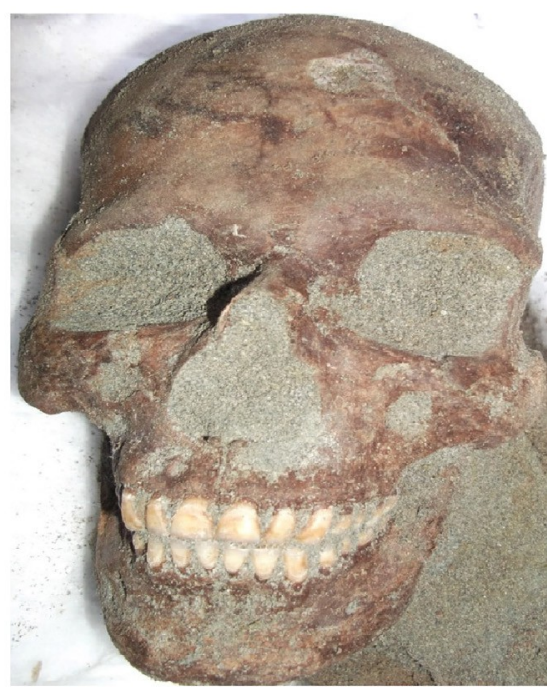

(b)

Fig. 5. (a) Entry wound on posterior aspect; (b): a taphonomic damage to a frontal skull ((Sehrawat et al., 2016), retrieve from Ajnala skeletal assemblage.
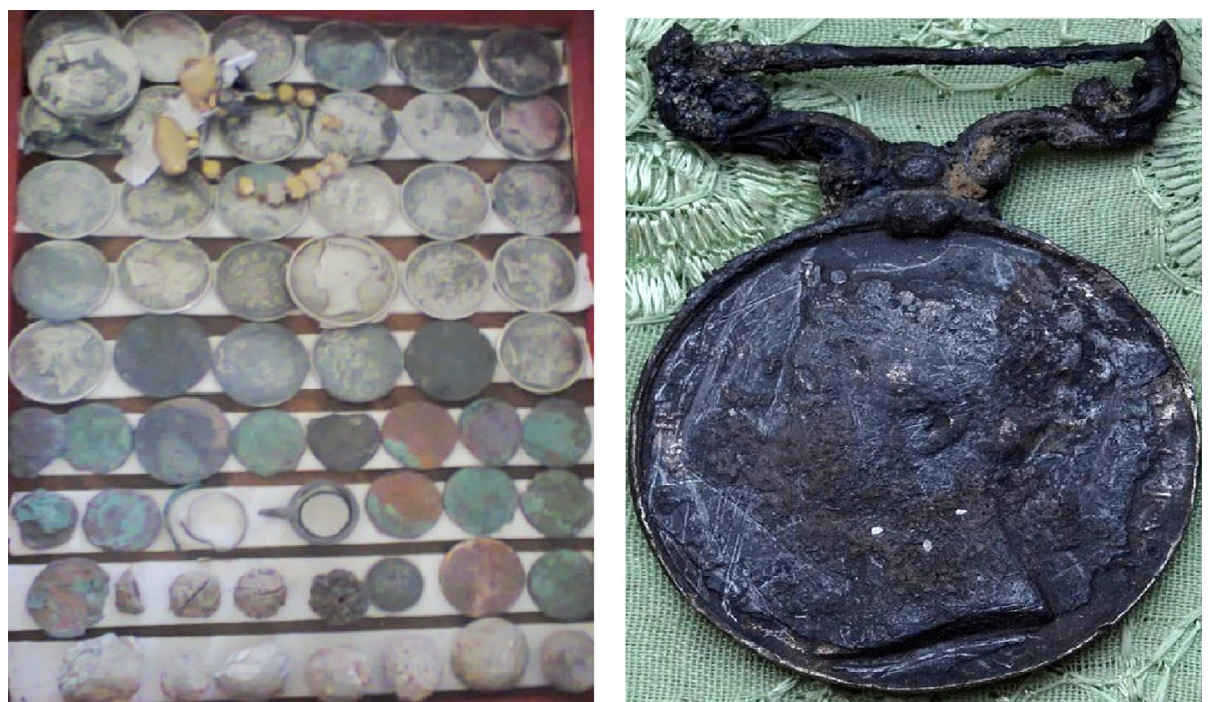

Fig. 6. Items of personal identity found associated with Ajnala skeletal remains.

\section{Discussions:}

\subsection{Forensic anthropological analyses:}

From the mandibular molar count $(\mathrm{N}=1476)$ only, it was found that the minimum number of individuals was $246(1476 / 6)$ which is slightly lesser than the reported number 
of 282 cadavers claimed in the book (Sehrawat et al., 2016). The differences could have been due to the inadvertent loss of some teeth during excavation process, methodological errors or due to incorrect number of the victims reported by Cooper (1858). The teeth embedded in some heavy blocks of soil containing various jaw fragments could not be considered for calculating the MNI (the same have now been collected). After their excavation in an unscientific manner, the recovered skeletal remains remain exposed to the taphonomic elements of very hot and humid conditions of the region for more than a year, which critically deteriorated the anatomical and morphological conformity of the remains. Besides colour changes, the bones may weather, crack, shrink, warp and get altered upon prolonged exposure to taphonomic factors like sun, wind, rain and humidity and it can affect interpretation of biological profile (Sehrawat and Pathak, 2017; Koch and Lambert, 2017). The entire excavation work was carried out by the non-professional archaeologists who inflicted some taphonomic damages to the human remains which complicated their distinction from traumatic injuries as a possible cause and manner of their death (as claimed in the book). The excavators were not well-versed with the importance of removal of complete articulated skeletons from the well sediments, so it resulted into heaps of badly damaged human remains (Sehrawat et al., 2016).

The skeletal features used for determining sexual affiliation of Ajnala skeletal remains have been commonly employed for sexing unknown human remains found in forensic or bioarchaeological contexts (Buikstra and Ubelaker, 1994; Rogers, 2005; Williams and Rogers, 2006; Garvin and Ruff, 2012; Kranioti et al., 2018). No pelvis could be retrieved in the Ajnala skeletal assemblage for their accurate sex estimation. Some contextual items recovered during excavation are similar to those predominately used by the males in present day Bengal, Bihar, Awadh (eastern UP) and north-eastern provincial states of India and thus, were suggestive of being used by males whose remains have been recovered from the disused well. These results substantiated the written records that the Ajnala skeletal remains belonged to male sepoys massacred by the colonial rulers. Some vertebrae, cranial segments, long bones, hand and foot bones were excessively larger in size and contour; probably they belonged to individuals of West Asian or Iranian origin generally being tall statured with sturdy body-builds. However, any inference drawn about population affinity of these remains solely on the basis of assumed correlations between the shape and size of skeletal elements can be erroneous as Ajnala remains came from a population who lived during the 19th century.

The traumatic injuries on the frontal and posterior cranial portions corroborated the written accounts that the mutineer sepoys were killed from the volleys of distant musketry firings (Cooper, 1858). Postmortem nature of some cranial injuries was due to non-scientific excavation of the remains. The recovery of the army medals established that the buried victims had military/army affiliations. Few amateur historians questioned the credibility of the written records and argued that these remains belong to the victims of Hindu-Muslim partition conflicts of August 1947 when India got independence from the decades-old colonial rule and the country was divided into nations i.e., Hindustan and Pakistan. Neither the reported manner of death nor their post-1857 burial period could be confirmed from the traumatic lesions on the recovered crania or from the years of make indented on the recovered coins and medals, respectively (Sehrawat et al., 2016). Low frequencies of different dental pathologies in Ajnala skeletal remains implied that the victims had fairly good dental health, better childhood living conditions and healthy dietary habits (Sehrawat and Singh, 2018). These observations supported the general view that only healthy individuals got opportunity to be recruited as sepoys in the army and their consequent improved economic status helped them maintain good dental hygiene till their execution by 
the colonial rulers in 1857.

\subsection{Skeletal and odontological age estimations:}

The age of the skeletal remains was estimated from the pulp-tooth area ratio (PTR) of molars, elemental profile and the average attrition stage (ASA) method of molars (Sehrawat et al., 2017; Sehrawat and Singh, 2020). Any of these methods when applied individually, cannot provide accurate age estimates for forensic purposes ( $\mathrm{Li}$ and Ji, 1995; Singh and Chavali, 2011; Tuteja et al., 2012), however, the combined approach of using all such methods helped the authors to estimate the probable age of Ajnala victims and to draw some conclusions about their sub-adult or adulthood nature. The other morphological age estimation methods considered accurate for ageing (based on stages of auricular surface and the pubic symphysis of pelvis) couldn't be applied as no complete pelvis was retrieved from badly damaged and commingled human remains. The existence of sub-adult skeletons (?) in the assemblage was contrary to the written accounts and these inconsistencies may be due to limitations of the methods used, methodological/observer errors or due to inaccurately reported age thresholds of victims in the book (Cooper, 1858). Also, it cannot be denied that cadaveric remains of some young sub-adults might have already been present into the said abandoned well before the corpses of Ajnala victims were thrown into it. There might be some truth in the ceremonial or murderous killing hypothesis put forth by some locals who stressed that the reported abandoned well had been used as a common burial site for clandestine disposal of cadavers/disguised killings by some social classes or the criminals to evade the attentions of the state authorities. From the preliminary forensic anthropological examinations of the retrieved human remains and the contextual evidences recovered from the site, a number of queries as stated above remain unanswered till-date. 
Table 1

Calibration of C-14 AMS dates for some dentine collagen samples extracted from Ajnala teeth.

\begin{tabular}{|c|c|c|c|c|c|c|c|c|c|c|}
\hline $\begin{array}{l}\text { AMS C-14 } \\
\text { Lab. code }\end{array}$ & Sample ID/info & $\begin{array}{l}\text { pMC absol. } \\
(\%)( \pm 1 \sigma)\end{array}$ & $\begin{array}{l}\text { pMC abs. } \\
\text { (unc.)(1 s) }\end{array}$ & $\begin{array}{l}\text { Conven. C-14 age } \\
\text { (BP) }( \pm 1 \sigma)\end{array}$ & $\begin{array}{l}\text { Age Unc. } \\
(1 \mathrm{~s})+-(\mathrm{yr})\end{array}$ & & $\begin{array}{l}\text { Two sigma } \\
\text { Calibrated ages* }\end{array}$ & Probability & Maximum cal age (cal AD) & Minimum cal age (cal AD) \\
\hline DeA-22248 & $\mathrm{AJ}-06$ & 99.4193 & 0.316759 & 46.78565 & 25.59367 & & $\begin{array}{l}\text { [cal CE 1696: cal CE 1726] } \\
\text { [cal CE 1813: cal CE 1838] } \\
\text { [cal CE 1842: cal CE 1853] } \\
\text { [cal CE 1868: cal CE 1873] } \\
\text { [cal CE 1876: cal CE 1918] } \\
\text { [cal CE 1955: cal CE 1956] }\end{array}$ & $\begin{array}{l}0.197 \\
0.139 \\
0.024 \\
0.009 \\
0.616 \\
0.014\end{array}$ & 1696 & 1956 \\
\hline DeA-22249 & AJ-06_R & 100.629 & 0.302506 & -50.4084 & 24.14808 & -18.1306 & [cal CE 1954: cal CE 1956] & 1.000 & 1954 & 1956 \\
\hline DeA-22250 & AJ-07 & 99.9467 & 0.291093 & 4.278698 & 23.39578 & -23.9353 & $\begin{array}{l}\text { [cal CE 1711: cal CE 1717] } \\
\text { [cal CE 1829: cal CE 1831] } \\
\text { [cal CE 1890: cal CE 1909] } \\
\text { [cal CE 1955: cal CE 1957] }\end{array}$ & $\begin{array}{l}0.014 \\
0.004 \\
0.431 \\
0.551\end{array}$ & 1711 & 1957 \\
\hline DeA-22251 & $\mathrm{AJ}-08$ & 99.3033 & 0.301167 & 56.15874 & 24.36221 & -20.1368 & $\begin{array}{l}\text { [cal CE 1695: cal CE 1721] } \\
\text { [cal CE 1813: cal CE 1838] } \\
\text { [cal CE 1842: cal CE 1853] } \\
\text { [cal CE 1868: cal CE 1874] } \\
\text { [cal CE 1875: cal CE 1918] } \\
\text { [cal CE 1955: cal CE 1956] }\end{array}$ & $\begin{array}{l}0.214 \\
0.153 \\
0.030 \\
0.015 \\
0.579 \\
0.008\end{array}$ & 1695 & 1956 \\
\hline DeA-22252 & AJ-15 & 98.7602 & 0.301165 & 100.216 & 24.49609 & -26.0608 & $\begin{array}{l}\text { [cal CE 1686: cal CE 1731] } \\
\text { [cal CE 1808: cal CE 1927] }\end{array}$ & $\begin{array}{l}0.279 \\
0.721\end{array}$ & 1686 & 1927 \\
\hline DeA-22253 & AJ-14 & 99.0032 & 0.301068 & 80.47554 & 24.42805 & -22.1591 & $\begin{array}{l}\text { [cal CE 1693: cal CE 1727] } \\
\text { [cal CE 1812: cal CE 1919] } \\
\text { [cal CE 1955: cal CE 1955] }\end{array}$ & $\begin{array}{l}0.257 \\
0.721 \\
0.000\end{array}$ & 1693 & 1955 \\
\hline DeA-22254 & AJ-16 & 100.127 & 0.313339 & -10.2094 & 25.13832 & -19.6101 & $\begin{array}{l}\text { [cal CE 1893: cal CE 1904] } \\
\text { [cal CE 1954: cal CE 1956] }\end{array}$ & $\begin{array}{l}0.167 \\
0.833\end{array}$ & 1893 & 1956 \\
\hline DeA-22255 & $\mathrm{AJ}-20$ & 98.8207 & 0.30979 & 95.29752 & 25.1822 & -17.9847 & $\begin{array}{l}\text { [cal CE 1687: cal CE 1730] } \\
\text { [cal CE 1809: cal CE 1926] }\end{array}$ & $\begin{array}{l}0.273 \\
0.727\end{array}$ & 1687 & 1926 \\
\hline DeA-22256 & AJ-22 & 99.2302 & 0.305121 & 62.07305 & 24.70027 & -17.2166 & $\begin{array}{l}\text { [cal CE 1695: cal CE 1726] } \\
\text { [cal CE 1813: cal CE 1839] } \\
\text { [cal CE 1841: cal CE 1854] } \\
\text { [cal CE 1859: cal CE 1861] } \\
\text { [cal CE 1867: cal CE 1918] } \\
\text { [cal CE 1955: cal CE 1956] }\end{array}$ & $\begin{array}{l}0.230 \\
0.169 \\
0.041 \\
0.005 \\
0.551 \\
0.006\end{array}$ & 1695 & 1956 \\
\hline DeA-22257 & $\mathrm{AJ}-25$ & 93.9308 & 0.291102 & 502.9533 & 24.89496 & -22.1453 & [cal CE 1405: cal CE 1443] & 1.000 & 1405 & 1443 \\
\hline
\end{tabular}

pMC absol.- Percent Modern Carbon; Conven.-Conventional; Unc.-uncertainty; yr- Year.

*http:/ / calib.org/CALIBomb/ (Reimer et al., 2004, 2013; Hua et al., 2013). 


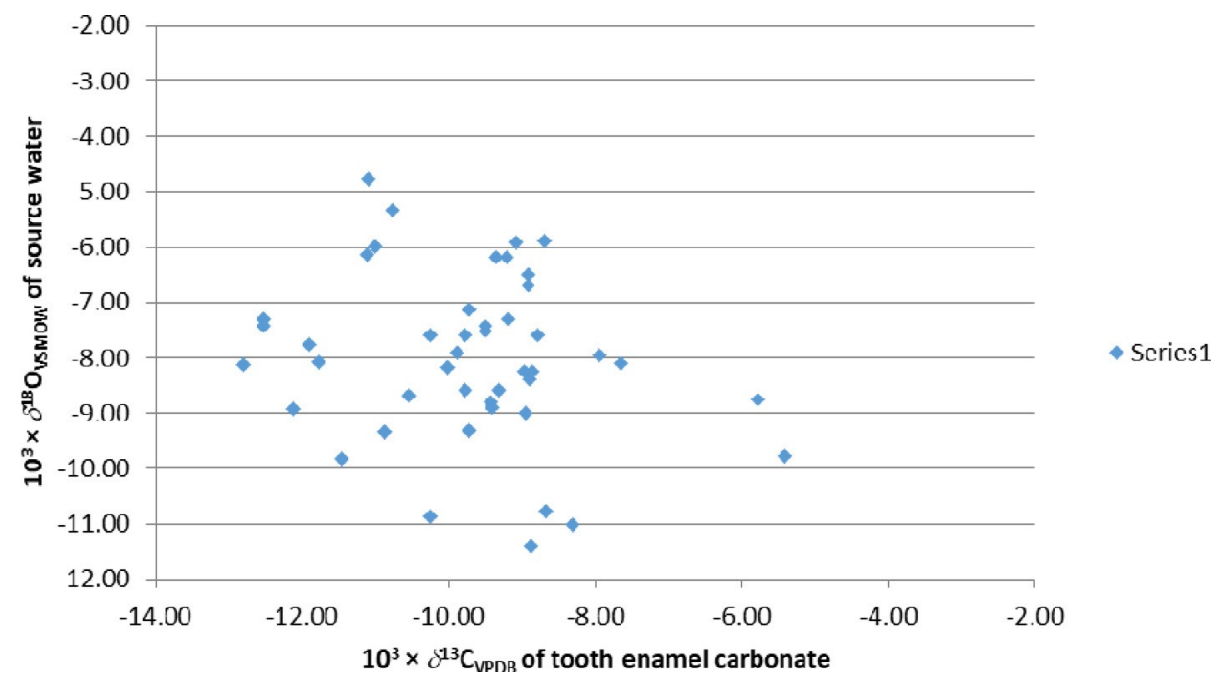

Fig. 7. Plot of $\delta 13 \mathrm{C}$, and $\delta 18 \mathrm{O}$ isotopic signatures in teeth Ajnala samples.

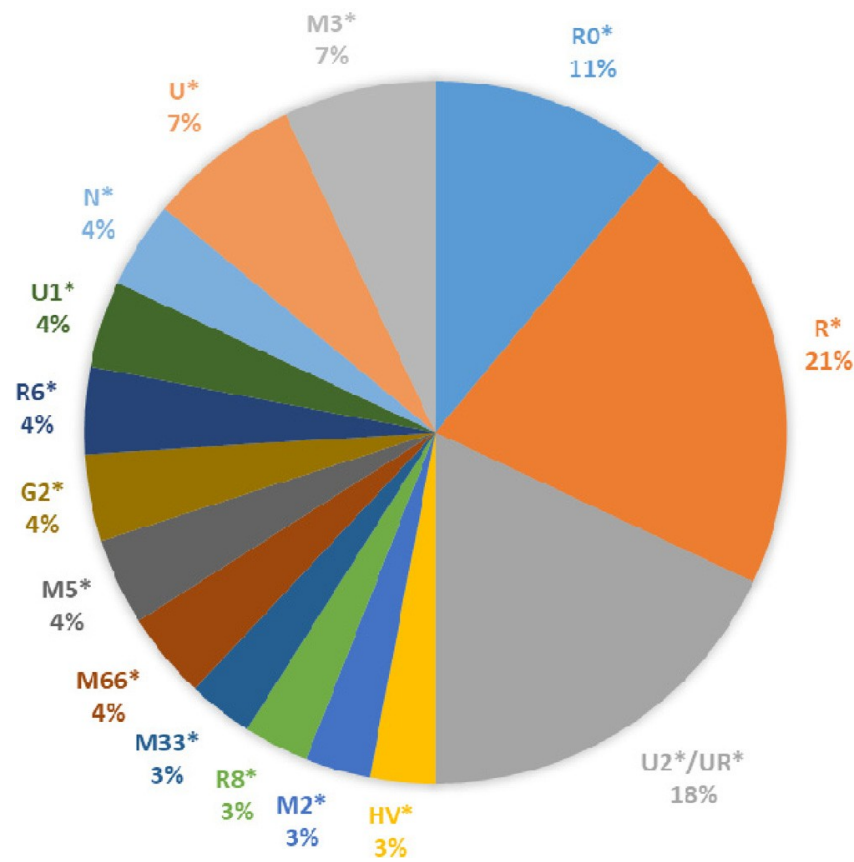

Fig. 8. Distribution pattern of mtDNA haplogroups in Ajnala samples. 


\subsection{Stable isotope analyses}

Stable isotope analysis has contributed significantly in geographical provenancing of unknown human remains recovered from forensic or bio-archaeological contexts (Meier-Augenstein and Fraser, 2008; Alkass et al., 2013; Bartelink et al., 2014, 2018; Kamenov and Curtis, 2017; Meier-Augenstein, 2018). The estimated tooth enamel carbonate $\delta{ }^{18}$ Ovsmow values of Ajnala teeth are typically associated with precipitation and/or snowfall of inland regions; some distance away from the coast. The aforementioned $\delta{ }^{18}$ Ovsmow value range for source water is indeed

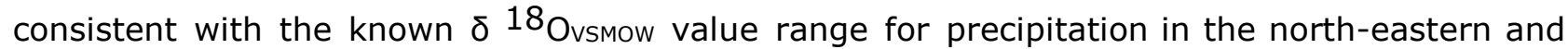
eastern regions of India (Bowen, 2019). In the context of artefacts recovered from the well (a mass grave), this information could be interpreted as corroboration of the hypothesis that the remains are indeed those of the soldiers recruited from Indian states of Orissa, West Bengal, Bihar, Awadh, Meghalaya, and Manipur and other north-eastern and coastal states. Analysis of individuals' $\delta{ }^{13} \mathrm{C}$ values reflecting the averaged dietary ${ }^{13} \mathrm{C}$ signal showed no correlation with observed corresponding $\delta 1^{18}$ Ovsmow values and, therefore, no correlation with proposed geographic origin. Thus, $\delta 180$ values were consistent with the north-eastern and eastern states of India and this information can be used only as corroborating evidence i.e. as one piece fitting together with other independent pieces of information (e.g. artefacts recovered from the mass grave such as uniform buttons) that would point towards the remains being those of the soldiers killed in a mass execution.

The stable isotopic results indicated that the victims lived in a similar geographic area, most likely during their childhood; and also they inhabited wider variety of places during the last 10 years of their lives (Sehrawat and Sankhyan, 2020). Thus, the victims supposedly belonged to a specific geographical region of India as reported in written accounts that victims army recruits belonging to 26th Native Bengal Infantry battalion having soldiers coming from the mentioned Indian territories; short distances away from the coastal boundary of Bay of Bengal (Sehrawat and Sankhyan, 2020). Thus, small sample stable isotope results indicated that the studied teeth belonged to the geographical area of India as mentioned by Cooper [1]. The stable isotope analysis of carbon, nitrogen, oxygen, strontium and sulfur with larger samples of teeth and bone samples is underway to provide detailed information about the geographical identity, migration history and dietary patterns of these non-scientifically excavated human skeletal remains.

\subsection{Molecular analysis}

Archaeo-genetic methods can provide important leads in biological profiling of unknown remains when anthropological analyses suffer some limitations. The possibility of extraction and sequencing of mtDNA from the bio-archaeological samples have opened up new possibilities for expanding our understanding of forensic archaeology.

The inconsistencies between the forensic anthropological observations and the written facts about the identity affiliations of the Ajnala skeletal remains (Cooper, 1858), encouraged the authors to carry out more advanced scientific analyses with them for a more reliable, accurate, reproducible, scientifically valid and acceptable biological identity of the remains.

Haplogroups are the genetic signatures in form of different combination of DNA mutations in mtDNA which are taken as the branches on the tree of early human migrations and genetic evolution and their distribution pattern, often, have a geographic relation (Mitchell et al., 2014). They link the members of a haplogroup back to first appearance of the marker in the group's 
most recent common ancestor. Thus, anthropological observations were further verified by the distribution pattern of some haplogroups in mtDNA sequences of Ajnala teeth samples. The mtDNA haplogroup results were inconsistent with the written versions which mentioned that the 26th North Infantry battalion sepoys belonged to Bengal, Bihar, Orissa and Awadh and some north-eastern states of India. Some of the samples also possessed 'RO' haplogroup, (an ancestral clade of HV haplogroup); and today this haplogroup mainly occurs among the Soqotri Kailash people of South Asia, dwelling in northern Pakistan, which was part of India before independence of Hindustan in 1947. No changes have been anticipated between the genetic composition of present day individuals and the 162-year-old skeletal remains of the individuals belonging to the same geographical area. The mtDNA analysis of very few molars from a total assemblage of more than six thousand teeth recovered from the abandoned well cannot be the true representative of entire Ajnala skeletal collection (Sehrawat and Sankhyan, 2020). So, valid conclusions about their identity affiliations can be suggested only when all teeth and bone samples will be processed for their mtDNA analyses.

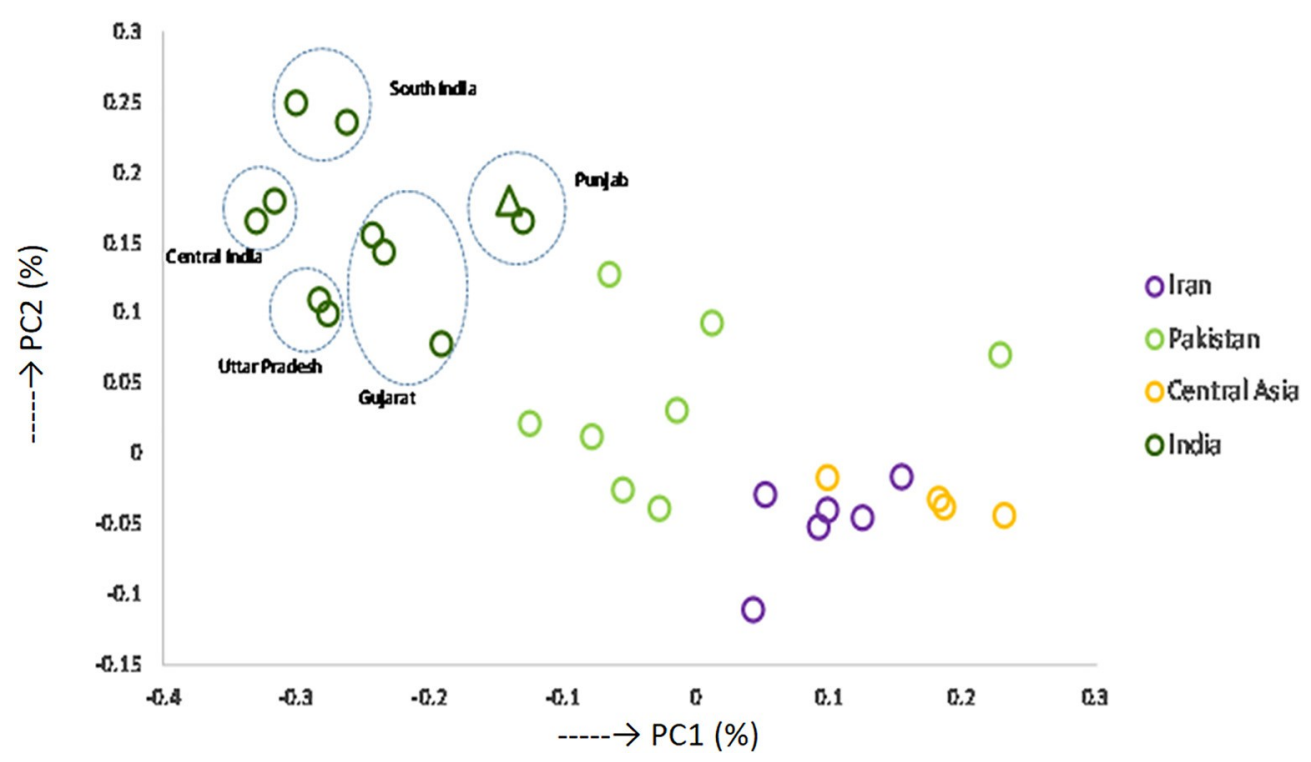

Fig. 9. Principal Component Analysis (PCA) of mtDNA haplogroup frequencies in the studied Ajnala teeth samples. 


\section{Conclusions}

This article illustrates the application of different scientific techniques for identification strategies of the challenged human remains, excavated from an abandoned well at Ajnala (Amritsar, India). From their preliminary anthropological, radiological, chemical and molecular analyses, it appears that the accurate and reliable identity establishment of these remains seems to be a distant reality as thousands of remains need to be analyzed for that purpose. The badly damaged and commingled nature of the remains is the primary obstacle which has hindered their identification to be a difficult task for the investigators. The absence of biological profilespecific bones like pelvis, skull or long bones, the commingled nature of remains, lack of antemortem in- formation about the demographic credentials of the victims, unavailability of the list of names and addresses of martyred sepoys from England, and probable difficulties in tracking down the direct descendants of the victims etc., are the major challenges faced towards ac- curate biological profiling of these remains. The varying versions put forth by few amateur historians about the timings and causation of Ajnala skeletal remains have further complicated the identification endeavours. More sophisticated scientific examinations (like whole- genome sequencing) of the entire skeletal assemblage, along with the contextual items are expected to be carried out extended for many more years to provide accurate and valid scientific identity to these remains. It is certainly going to be a very challenging and expensive task for the investigators to work with such a huge collection of badly damaged and fragmented human remains, and endorse or refute any of the origin hypotheses about their populational affiliations. Despite having carried out so many scientific analyses with these remains, the identity establishment of Ajnala skeletal remains still remains a forensic anthropological puzzle to be solved from further scientific analyses of all the human remains and other pieces of evidence (like coins, medals, finger- rings, bracelets, stone projectiles etc.) recovered from the site. The whole genome sequencing of mtDNA data obtained from all the molar teeth and bones, and their comparisons with the available/developed databases is the only option left with the investigators to clear the confusions about the biological identity of Ajnala skeletal remains. Thus, it would be an unqualified and sweeping conclusion to claim their identity as adult or non-adult, male or female, local or non-local, victims of 1857 mass killings or to the victims of ceremonial sacrifices or criminal activities committed in the past on the basis of scientific analyses of few human remains collected from a huge collection of skeletal and dental remains.

\section{Novelty statement}

The present article describes the application of multiple techniques for forensic anthropological identification of unknown human remains excavated from an abandoned well. It is the first forensic anthropological case report from India and the observations presented therein will provide future directions to be adopted by experts for identification of badly damaged and comingled human remains recovered in forensic or bio-archaeological contexts.

\section{Author statements}

The present article describes the application of multiple techniques for forensic anthropological identification of unknown human remains excavated from an abandoned well. It is the first forensic anthropological case report from India and the observations presented therein will provide future directions to be adopted by experts for identification of badly damaged and comingled human remains recovered in forensic or bio-archaeological contexts. 
The authors declare that they have no known competing financial interests or personal relationships that could have appeared to influence the work reported in this paper.

\section{Acknowledgements}

The first author (JS) is highly thankful to SERB-DST, New Delhi for financial support sanctioned in the form of 'Core Research Grant' (Animal Sciences) vide Grant No SERB/F/4790/2018-2019, which helped in conceptualization, experimentation and designing the present brief communication. Authors are highly thankful to Prof. Eric Bartelink, California State University, Chico (CA), for providing valuable suggestions and interpretations regarding stable isotope analysis. Prof. Devinder Mehta, Dean, Faculty of Sciences and Sh. Navtej Singh, Macrographer, Department of Physics, Panjab University, Chandigarh, helped in giving innovative ideas for conceptualization and writing this manuscript. Authors wish to thank all the individuals who gave their consent for using their extracted and 'to-be-discarded' teeth for this study. We are also highly thankful to the staff at Oral Health Centre of Government Medical College and Hospital, Sector-32, Chandigarh, India, for their support in collecting the modern molar teeth samples. We extend our heartiest thanks to Prof. Chris O Hunt, Liverpool John Moores University and Prof. Paula Reimer, Queen's University Belfast, for helping us in calibrating and interpreting probable calendar ages of C-14 dates of few teeth samples. Heartiest thanks are also extended to Dr. Rajesh Agnihotri, Scientist E, Birbal Sahni Institute of Paleosciences, Lucknow (India) for helping us in encapsultation of prepared collagen samples. Authors are highly thankful and indebted to the anonymous reviewers whose valuable suggestions and scientific inputs helped the authors to further improve the readable and intelligible scientific quality of this manuscript.

\section{Appendix A. Supplementary data}

Supplementary data to this article can be found online at https:// doi.org/10.1016/j.jasrep.2020.102434.

\section{References}

Ajmal, M., Mody, B., Kumar, G., 2001. Age estimation using three established methods: a study on Indian population. Forensic Sci. Int. 122 (2-3), 150-154.

Alkass, K., Saitoh, H., Buchholz, B.A., Bernard, S., Holmlund, G., Senn, D.R., Spalding, K.L., Druid, H., 2013. Analysis of radiocarbon, stable isotopes and DNA in teeth to facilitate identification of unknown decedents. PLOS One 8 (7).

Babshet, M., Acharya, A., Naikmasur, V., 2011. Age estimation from pulp/tooth area ratio in an Indian sample: a preliminary comparison of three mandibular teeth used alone and in combination. J Forensic Leg. Med. 18, 350-354.

Bandyopadhyay, E., Sehrawat, J.S., Rai, N., Raghavan, M., 2017. Ancient genomics in India: clarifying the maternal origins of 160 -year-old human remains. Canad. J. Biotech. 1, 13.

Bartelink EJ, Berg GE, Chesson LA, Tipple BJ, Beasley MM, Prince-Buitenhuys JR, MacInnes $\mathrm{H}$, MacKinnon AT, Latham KE. Applications of stable isotope forensics for geolocating unidentified human remains from past conflict situations and large-scale humanitarian efforts. In: Latham KE, Bartelink EJ, Figgegan M (eds.): New Perspectives in Forensic Human Skeletal Identification, 1st Edn, Elsevier. https://doi.org/10.1016/B978-0-12-805429-1.00015-6 ; 2018:175-184.

Bartelink, E.J., Berry, R., Chesson, L.A., 2014. Stable isotopes and human provenancing. 
In: Mallett, X., Blythe, T., Berry, R. (Eds.), Advances in Forensic Human Identification. Boca Raton, Taylor and Francis, pp. 157-184.

Bates $C$, Carter $M$. The mutiny at the margins: New perspectives on the Indian uprisings of 1857; 7th vol., Documents of the Indian uprising. Sage Publications India Pvt. Ltd; New Delhi; 2017: pp. 124-132.

Bowen GJ. The Online Isotopes in Precipitation Calculator, version 3.1, 2019; http://www.waterisotopes.org

Buikstra, J.E., Ubelaker, D.H., 1994. Standards for data collection from human skeletal remains: proceedings of a seminar at the Field Museum of Natural History. Arkansas Archaeological Survey Fayetteville, AR.

Chenery, C.A., Pashley, V., Lamb, A.L., Sloane, H.J., Evans, J.A., 2012. The oxygen isotope relationship between the phosphate and structural carbonate fractions of human bioapatite. Rapid Commun. Mass Spectrom. 26 (3), 309-319.

Cooper, F., 1858. The Crisis in the Punjab: From $10^{\text {th }}$ of May Until the Fall of Delhi. Smith Elders \& Co., London, pp. 151-170.

Coplen, T.B., 2011. Guidelines and recommended terms for expression of stable-isotoperatio and gas-ratio measurement results. Rapid Commun. Mass Spectrom. 25 (17), 2538-2560.

Daux, V., Lecuyer, C., Heran, M.A., Amiot, R., et al., 2008. Oxygen isotope fractionation between human phosphate and water revisited. J. Hum. Evol. 55 (6), 1138-1147.

Garvin, H.M., Ruff, C.B., 2012. Sexual dimorphism in skeletal brow-ridge and chin morphologies determined using a new quantitative method. Am. J. Phys. Anthropol. $147,661-670$.

Hua, Q., Barbetti, M., Rakowski, A.Z., 2013. Atmospheric radiocarbon for the period 1950-2010. Radiocarbon 55 (4), 2059-2072. https://doi.org/10.2458/azu_js_rc. v55i2.16177.

Kamenov, G.D., Curtis, J.H., 2017. Using carbon, oxygen, strontium, and lead isotopes in modern human teeth for forensic investigations: a critical overview based on data from Bulgaria. J. Forensic Sci. https://doi.org/10.1111/15564029.13462.

Koch, S., Lambert, J., 2017. Detection of skeletal trauma on whole pigs subjected to fire environment. J. Anthropol. Rep. 2 (1), 113.

Kranioti, E.F., Garcia-Donas, J.G., Can, I.O., Ekizoglu, O., 2018. Ancestry estimation of three Mediterranian populations based on cranial metrics. Forensic Sci. Intl. 265 (e1265), e8.

Li, C., Ji, G., 1995. Age estimation from permanent molar in northeast China by the method of average stage of attrition. Forensic Sci. Int. 75, 186-196.

Meier-Augenstein, M., 2018. Isotope Forensics: Methods and Forensic Applications of Stable Isotope Analysis, 2nd ed. John Wiley \& Sons. https://onlinelibrary.wiley.com/ doi/book/10.1002/9781119080190.

Meier-Augenstein, W., Fraser, I., 2008. Forensic isotope analysis leads to identification of a mutilated murder victim. Sci. Justice 48 (3), 153-159.

Meier-Augenstein, W., Schimmelmann, 2019. A guide for proper utilisation of stable isotope reference materials. Isotopes Environ. Health Stud. 55 (2), 113-128.

Mitchell, S.L., Goodloe, R., Brown-Gentry, K., Murdock, D.G., Crawford, D.C., 2014. 
Characterization of mitochondrial haplogroups in a large population-based sample from the United States. Human Genet. 133 (7), 861-868.

Reimer, P.J., Brown, T.A., Reimer, R.W., 2004. Discussion and reporting of post-bomb C- 14 data. Radiocarbon 46, 1299-1304.

Reimer, P.J., Bard, E., Bayliss, A., Beck, J.W., Blackwell, P.G., Bronk Ramsey, C., Buck, C.E., Cheng, H., Edwards, R.L., Friedrich, M., Grootes, P.M., Guilderson, T.P., Haflidason, H., Hajdas, I., Hatté, C., Heaton, T.J., Hogg, A.G., Hughen, K.A., Kaiser, K.F., Kromer, B., Manning, S.W., Niu, M., Reimer, R.W., Richards, D.A., Scott, E.M., Southon, J.R., Turney, C.S.M., van der Plicht, J., 2013. IntCal13 and MARINE13 radiocarbon age calibration curves 0-50000 years calBP. Radiocarbon 55 (4), 1869-1887.

https://doi.org/10.2458/azu_js_rc.55.16947.

Rogers, T.L., 2005. Determining sex of human remains through cranial morphology. J Forensic Sci. 50 (3), 493-500.

Sehrawat, J.S., Pathak, R.K., Kaur, J., 2016. Human remains from Ajnala, India, 2014: Short fieldwork report. Bioarchaeol. Near East 10, 82-90.

Sehrawat JS, Singh M, Pathak RK. Age estimation from pulp-tooth area ratio (PTR) of the canines collected from the Ajnala skeletal remains: A forensic anthropological case report. In: Anthropology and Forensic Science: The Current Dynamism. Kapoor et al (eds).

Selective \& Scientific Books publishers, New Delhi, pp, 111-119, 2017.

Sehrawat, J.S., Pathak, R.K., 2017. Non-scientific archaeological recovery of the human remains from an ancient well in India: challenges in their identification. Archaeol. Environ. Forensic Sci. 1 (1), 79-92.

Sehrawat, J.S., Sankhyan, D., 2020. Forensic anthropology in investigations of crimes against humanity: Global dimensions and the Mid-19 $9^{\text {th }}$-Centuary Ajnala (India) massacre. Forensic Sci. Rev. 32, 105-133.

Sehrawat, J.S., Singh, M., 2018. Dental health status of skeletal remains excavated from an abandoned well at Ajnala, India: a bio-archaeological study. Anthropol. Rev. 81 (3), 307-324.

Sehrawat, J.S., Singh, M., 2020. Application of trace elemental profile of known teeth for sex and age estimation of Ajnala skeletal remains: a forensic anthropological crossvalidation study. Biological Trace Element Res. 193 (2), 295-310. https://doi.org/10. 1007/s12011-019-01712-8.

Sehrawat, J.S., Singh, M., 2019. Forensic odontological sex determination of Ajnala skeletal remains based on the statistical equations generated from the odontometrics of known teeth. Forens. Sci. Int. Reports 1 (100044). https://doi.org/10.1016/j.fsir. 2019.100044.

Singh, J., Chavali, K.H., 2011. Age estimation from clavicular epiphyseal union sequen- cing in a Northwest Indian population of the Chandigarh region. J. Forensic Leg. Med. 18, 82-87.

Tamang, R., Chaubey, G., Nandan, A., Govindraj, P., et al., 2018. Reconstructing the demographic history of the Himalayan and adjoining populations. Human Genet. 137 (2), 129-139.

Tuteja, M., Bahirwani, S., Balaji, P., 2012. An evaluation of third molar eruption for assessment of chronologic age: a panoramic study. J. Forensic Dent. Sci. 4 (1), 1318.

Williams, B.A., Rogers, T.L., 2006. Evaluating the accuracy and precision of cranial morphological traits for sex determination. J. Forensic Sci. 51 (4), 729-735. 


\section{Appendix A}

\section{Stable Isotope analysis:}

The selected bone and tooth samples were powdered separately with agate pestle mortar and the powdered samples were kept in air tight centrifuge tubes to prevent any contamination. The organic and inorganic fractions were separated using standardised techniques. The stable isotopic ratios of Carbon $(\delta 13 \mathrm{C})$ and Oxygen $(\delta 18 \mathrm{O})$ of tooth and bones were measured at the stable isotope facility at the Wadia Institute of Himalayan Geology, Dehradun (WIHG) using gas source continuous flow Isotope Ratio Mass Spectrometer (CF-IRMS) through Gas Bench.

Approximately $\sim 500 \mu \mathrm{g}$ samples were put in $12 \mathrm{ml}$ vials and kept at $72^{\circ} \mathrm{C}$ in Gas Bench tray and then flushed with ultrapure helium gas $(\geq 99.9995 \%)$ to remove all atmospheric gasses from the vials. Further $50-70 \mu \mathrm{L}$ phosphoric acid $((\geq 99 \%)$ were injected into the vials. All the samples were let up for 45 minutes at $72^{\circ} \mathrm{C}$ to equilibrate and to produce $\mathrm{CO}_{2}$ gas. The produced $\mathrm{CO}_{2}$ was introduced into the IRMS through GC column to analyze their isotopic ratio. The isotopic ratios of Carbon $(\delta 13 \mathrm{C})$ and Oxygen $(\delta 18 \mathrm{O})$ were obtained using the SSH correction (Santrock et al., (1985). All the samples were measured using sample - standard bracketing. The blank, in- House Standard (Merck- $\mathrm{CaCO}_{3}$ ), International Standard (NBS-18), and repeat samples were also run with each set of batch as QA/QC measure. Precision of these measurements are better than $\pm 0.1 \%$ for $\delta 13 \mathrm{C}$ and $\delta 18 \mathrm{O}$. The primary standard NBS-18 was run for the calibration whereas the in-House standard Merck-CaCO${ }_{3}$ was run at the interval of 10 samples to verify precision and quality of the measurement.

\section{MtDNA extraction:}

Pre cleaned tooth samples were placed in silicone rubber mould and left it for the one day. Once the tooth sample got completely settled, dermal cut off wheel was used to cut the tooth root. Through tooth root, a small hole was prepared using dremel bids and powder was made by engraving the pulp and dentine inner surface. About 50mg of powder was prepared and transferred in autoclaved eppendorf $(1.5 \mathrm{ml})$ tube. Complete powder was dissolved in $500 \mathrm{ml}$

of $0.5 \mathrm{mM}$ EDTA and incubated at $37^{\circ} \mathrm{C}$ using a rotatory shaker. After overnight incubation the lysate was centrifuged at $15,000 \mathrm{rpm}$ for 10 minutes. Supernatant was taken out and mixed with 5 volumes $(2.5 \mathrm{ml})$ of PB buffer (Qiagen), passed through silica column (Qiagen) and finally eluted out with $50 \mathrm{ml}$ of low TE buffer. Degraded ancient DNA samples were genotyped using Sequenom iPLEX assay and the Mass ARRAY system (SEQUENOM, San Diego, CA).

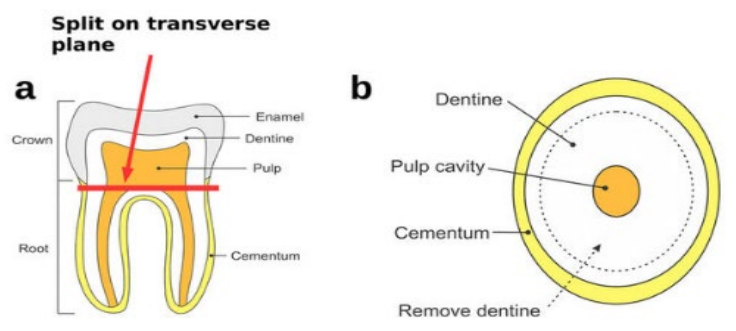

